\title{
La innovación financiera como fuente de riesgos en los mercados financieros globales
}

\author{
Financial innovation as a source of risks in global financial markets \\ Josué Cuatepotzo Méndez ${ }^{a}$, Esmeralda Pérez Villaseñor ${ }^{b}$
}

\begin{abstract}
:
At the end of World War II, the allies met in Bretton Woods to restructure the international monetary system, so they signed an agreement that established the US dollar as an international currency. As a result of the imbalances caused by this policy, in August 1971 the United States rescinded its commitment to exchange dollars for gold and decided to convert the dollar into a good like any other that is traded in the market and whose price is determined by the offer and the demand. Since then and hand in hand with financial innovation, risks and uncertainty in financial markets are increasing.
\end{abstract}

Keywords:

Financial globalization, risk, deregulation

\begin{abstract}
Resumen:
A finales de la Segunda Guerra Mundial, los aliados se reunieron en Bretton Woods para reestructurar el sistema monetario internacional, por lo que firmaron un acuerdo que estableció al dólar norteamericano como moneda internacional. Como consecuencia de los desequilibrios provocados por esta política, en agosto de 1971 Estados Unidos rescindió su compromiso de cambiar dólares por oro y decidió convertir el dólar en un bien como cualquier otro que se comercia en el mercado y cuyo precio es determinad o por la oferta y la demanda. Desde entonces y de la mano con la innovación financiera, los riesgos y la incertidumbre en los mercados financieros van en aumento.
\end{abstract}

Palabras Clave:

Globalización financiera, riesgo, desregulación

\section{Introducción}

El contexto de la globalización financiera y el surgimiento de la llamada economía digital nos obligan a analizar las tendencias en los mercados financieros para que las empresas estén preparadas ante los cambios vertiginosos del mundo de los negocios. En sentido, esta investigación tiene como objetivo realizar un análisis histórico del proceso de la globalización financiera para poder comprender, desde una perspectiva crítica, la ruta que se ha trazado desde la ruptura de los acuerdos de Bretton Woods y el impacto que la innovación financiera ha provocado en la generación de riesgos financieros. Los activos virtuales son un tema relativamente nuevo, por lo tanto, en México no existe suficiente información que explique su funcionamiento, tratamiento contable, marco legal, implicaciones fiscales y gestión de riesgos. Esto representa una desventaja para las empresas mexicanas, pues obstaculiza que reaccionen oportunamente para adoptar innovaciones de tecnología financiera y adaptarse rápidamente a los cambios en el entorno económico y financiero.

\section{El sistema monetario internacional a través del tiempo}

A finales de la Segunda Guerra Mundial, los aliados se reunieron en Bretton Woods para reestructurar el sistema monetario internacional. En esa época, Estados Unidos poseía la mayor parte de la oferta mundial de oro, por lo que firmaron un acuerdo que estableció al dólar norteamericano como moneda internacional. De ahí en adelante casi todas las transacciones internacionales se hicieron, y aún se hacen, en dólares. Cabe señalarque de esta conferencia nació el Fondo Monetario Internacional (FMI) y el Banco Internacional de Reconstrucción y

\footnotetext{
a Universidad Autónoma de Tlaxcala, Facultad de Ciencias Económico Administrativas, Contaduría Pública, Profesor de Finanzas. https://orcid.org/0000-0001-7155-018X,Email: josue.cuatepotzo@uatx.mx

b Universidad Autónoma de Tlaxcala, Facultad de Ciencias Económico Administrativas, Contaduría Pública, Profesora de TIC's. https://orcid.org/0000-0002-0256-8041,Email: nandy_armenta96@hotmail.com
} 
Fomento, el cual dio origen al Banco Mundial. Como consecuencia de los desequilibrios provocados por esta política, en agosto de 1971 Estados Unidos rescindió su compromiso de cambiar dólares por oro y decidió convertir el dólar en un bien como cualquier otro que se comercia en el mercado y cuyo precio es determinado por la oferta y la demanda.

Por otro lado, el auge petrolero en la década de 1970 marcó el principio de una oleada de préstamos por parte de bancos comerciales privados a países en vías de desarrollo como México. Esto se originó porque la Organización de Países Exportadores de Petróleo (OPEP) decidió aumentar el precio de los hidrocarburos, lo cual produjo una inmensa riqueza que en su mayoría fue depositada en la banca norteamericana. Como a mediados de esa década la economía norteamericana se encontraba en recesión, no había demanda de financiamiento interno. En consecuencia, los bancos estadounidenses voltearon a los países en vías de desarrollo, siempre escasos de capital, para brindarles financiamiento con altas tasas de interés; estos préstamos internacionales llegaron principalmente a México, Brasil y Argentina.

Algunos de los países del Tercer Mundo que estaban recibiendo los préstamos y usando sus recursos para su propio desarrollo, también se estaban beneficiando de los altos precios del petróleo. México es un claro ejemplo de esta situación, pues el gobierno calculó que tenía una buena capacidad crediticia y que podía utilizar los mismos ingresos petroleros para rembolsar sus créditos. Sin embargo, el problema vino más tarde cuando los países de la OPEP se equivocaron al calcular la elasticidad de la demanda del petróleo y, en consecuencia, el mercado petrolero se fue a pique y los precios cayeron con efectos catastróficos para México y su deuda externa.

Al estallar la crisis de la deuda, los bancos norteamericanos decidieron suprimir todo préstamo a cualquier país en vías de desarrollo y el FMl impuso, en el marco de los programas de ajuste estructural, la apertura de las naciones deudoras a las importaciones procedentes de todo el mundo, particularmente las de países desarrollados. Además, el FMI obligaba a eliminar los subsidios, aumentar los impuestos, recortar los salarios de las empresas de propiedad pública y aumentar los precios de los bienes y servicios suministrados por el sector público. En estas circunstancias, se facultó al FMI para vigilar que los países deudores adecuaran sus economías a través de cuatro reglas del liberalismo:

- Abrir su economía a la importación y a la inversión extranjera directa para responder a las exigencias de los países del centro (desarrollados).

- Fomentar la exportación para poder pagar la deuda.

- Equilibrar el presupuesto mediante la reducción del gasto público.

- Privatizar los bienes públicos.

Según Giddy (1994), las raíces de la internacionalización de los mercados pueden rastrearse desde el siglo XIX en que la emisión de bonos y acciones en mercados de Europa proporcionó recursos para el financiamiento del desarrollo de redes ferroviarias y obras importantes de infraestructura en América, Asia y otros países. 1

Durante siglos se consideró a los metales preciosos como base del sistema monetario de las naciones, sobre todo al oro y la plata. El aumento de las operaciones comerciales internacionales, el desarrollo tecnológico en la industria de la minería, los intereses geopolíticos de determinadas potencias (sobre todo quienes gozaban de una mayor posesión de oro), entre otros factores, propiciaron que a finales del siglo XIX se adoptara al oro como unidad monetaria de pago internacional denominado Patrón Oro Puro.

Al estallar la Primera Guerra Mundial en 1914, Estados Unidos y el Reino Unido suspendieron la libre circulación de oro a través de las fronteras debido a los gastos bélicos que la guerra implicaba por lo que las reservas de oro llegaron a ser tan solo una proporción mínima de los billetes en circulación, esto generó un papel de patrón moneda inconvertible.

Posteriormente, el 29 de octubre de 1929 quebró el mercado de valores de Nueva York, lo cual generó una intensa crisis económica conocida como la Gran Depresión, cuyos efectos cruzaron las fronteras norteamericanas. Esta crisis provocó que en muchos países se establecieran restricciones al comercio exterior y a los movimientos de capital, entre otras políticas proteccionistas. En consecuencia, entre 1929 y 1933, el comercio mundial descendió una tercera parte de su valor y dos tercios de su volumen. El impacto de la Gran Depresión generó que muchos países adoptaran patrones de papel moneda inconvertible, manejados por sus autoridades monetarias de acuerdo con las políticas económicas de cada nación.

Durante la Segunda Guerra Mundial el financiamiento de los gastos bélicos y de la reconstrucción posterior hizo crecer excesivamente la circulación monetaria. Antes de que concluyera la guerra se hicieron planes para organizar al sistema monetario internacional con el objeto de poner 
fin a la inestabilidad monetaria, a las restricciones cambiarias, a los controles de los movimientos de capital y a las barreras que obstaculizaban el comercio internacional.

Así, en la Conferencia de Bretton Woods, celebrada en julio de 1944, se creó un sistema base de tipos de cambio fijos que podían expresarse tanto en oro como en dólares estadounidenses, que pasaron a formar gran parte de las reservas monetarias de prácticamente todos los países. El dólar era convertible en oro en proporción de 35 dólares por onza troy de oro. Se crea así el Fondo Monetario Internacional como núcleo del sistema monetario mu ndial, con el propósito de controlar la liquidez internacional y el mantenimiento de un sistema de tipos de cambio.

Estados Unidos, por su parte, puso a disposición del mundo considerables cantidades de dólares. Una característica de la posguerra fue el persistente superávit de la balanza de pagos estadounidense debido a las cuantiosas exportaciones a Europa, pues la recuperación europea después de la guerra hacía imperativo comprar productos norteamericanos, pero se carecía de dólares para pagarlos, surgiendo así préstamos y donaciones de Estados Unidos, quien prestó a los países europeos enormes cantidades de capital a manera de ayuda de emergencia.

Posteriormente se comprendió que para evitar la propagación del socialismo en Europa debía hacerse algo más sistemático, por lo que en 1947 surgió el Plan Marshall, el cual incluyó a 16 países que se comprometieron a establecer un sistema multilateral de comercio y pagos para eliminar los controles contra los productos estadounidenses. Así Estados Unidos fue aprovechando su poder para satisfacer las necesidades de expansión de su economía. De esta forma el dólar se convirtió gradualmente en moneda internacional alcanzando la primacía que tuvo el oro hasta 1914 y la libra esterlina hasta 1939.

Los bancos centrales y privados empezaron a acumular dólares en sus reservas monetarias internacionales, lo que dio paso al establecimiento de bases para la existencia de un patrón de cambio dólar, el oro siguió siendo un medio de pago de aceptación mundial pero el dólar se convirtió en la principal moneda de reserva. Sin embargo, la reconstrucción económica de los países europeos permitió que estos fueran aumentando sus propias reservas monetarias internacionales (oro y dólares) mientras que la balanza de pagos de Estados Unidos se fue tornando deficitaria.
Entonces se empezó a cuestionar sobre la capacidad de que el dólar estadou nidense pudiera convertir en oro sus obligaciones en el exterior en cualquier momento. En 1968 las reservas de oro de Estados Unidos cubrían apenas poco mas de la tercera parte de sus obligaciones en el exterior, por lo que se pensó en la posibilidad de que el precio del oro se incrementara, lo que a su vez aumentó la demanda de oro para fines no monetarios. Al menguar las reservas de oro de Estados Unidos, la solidez del dólar experimentó un gran deterioro. El patrón monetario cambio oro se había convertido en un patrón político oro en el que existían tácitos "acuerdos de caballeros" que implicaban abstenerse de convertir las divisas en oro para evitar el derru mbamiento del sistema. Sin embargo, desde los años sesenta ocu rrieron canjes de dólares por oro en montos importantes y los bancos centrales mostraban menos disposición a acu mular dólares, por lo que Estados Unidos tuvo que liquidar con oro parte considerable de su déficit anual.

Ante esta situación, en un intento por contener la disminución de las reservas de oro, en marzo de 1968 se estableció un doble mercado para el oro. El oro alcanzó un alto precio que hacía cada vez más absurdo el precio de 35 dólares por onza troy fijado en 1934. De 1965 a 1967 el presidente Johnson formuló un programa de restricción voluntaria de las inversiones extranjeras directas estadounidenses, la cual se hizo obligatoria en 1968. Tantos controles tuvieron poco impacto, ya que la inversión estadounidense en el exterior se financiaba en muy pequeña medida con capital de este país, en consecuencia las empresas trasnacionales recu rrieron en mayor medida a préstamos en el exterior.

El sistema monetario internacional creado en Bretton Woods dependía de factores inestables, fuera de control y sin ninguna relación con las necesidades de liquidez, como:

- La convertibilidad del dólar en oro.

- El déficit de pagos estadounidenses.

- La decisión de los países de no convertir sus dólares en oro.

- Las variaciones en la cantidad de oro monetario, que dependía de su producción y su demanda privada.

Mas tarde se creó un nuevo medio de pago internacional, los Derechos Especiales de Giro (DEG), con esto se tuvo la esperanza de que las reservas monetarias aumentaran en la medida necesaria sin que Estados Unidos tuviera déficit de pagos, así como mantener la convertibilidad del dólar sin disminuir sus tenencias de oro. No obstante, a finales de la década de los sesenta, era ya evidente que 
el sistema capitalista estaba en los albores de una aguda crisis.

El 15 de agosto de 1971 el presidente Nixon anunció un programa de acción gubernamental: la "nueva política económica". La nueva política incluyó el establecimiento de una sobretasa a los impuestos sobre cierto tipo de importaciones, con el propósito de que Japón y Europa revaluaran sus divisas, dando así una ventaja competitiva a los productos estadounidenses.

Paralelamente, el gobierno de Estados Unidos decidió suspender la convertibilidad del dólar en oro, para quitar a los especuladores el incentivo de convertir sus dólares en su equivalente de oro. Así, el gobierno estadounidense suspendió de manera unilateral el sistema monetario internacional surgido en Bretton Woods en 1944, basado en paridades fijas acordadas con el Fondo Monetario Internacional y en la convertibilidad en oro de las tenencias oficiales de dólares, dejando al mundo inundado de dólares sin respaldo en oro, situación que desencadenó una inflación internacional.

Posteriormente, en el llamado acuerdo Smithsoniano de diciembre de 1971, se reconoció oficialmente la devaluación del dólar (8.75\%) y se revaluaron las divisas de los restantes países del G-10 (Estados Unidos, Canadá, República Federal Alemana, Japón, Reino Unido, Francia, Italia, Países Bajos, Bélgica y Suecia) con lo cual se establecieron nuevos tipos de cambio fijo para las diez monedas más importantes del mundo capitalista (Chapoy, 2001). En el acuerdo de Bretton Woods se permitía una fluctuación de $1 \%$ mientras en el Smithsoniano ese margen se amplió a 2.25\%.

Con la rescisión de los acuerdos de Bretton Woods se adoptó un sistema basado en los tipos de cambio fluctuantes y la libre movilidad de las corrientes de capital, el cual se ha denominado como el régimen dólar-Wall Street, según Puyana (2002). 2

En 1972, Inglaterra declinó como potencia económica y en marzo de 1973 las 14 naciones no socialistas más ricas del mundo llegaron a una serie de acuerdos tendientes a evitar nuevas crisis monetarias. Dichas naciones se basaron en el mutuo apoyo y en la flotación de sus divisas, lo que significó que las autoridades monetarias de dichos países decidieron dejar de defender el valor en dólares de sus monedas dentro de los márgenes fijos. Aunque se esperaba que la flotación fuera temporal, posteriormente fue oficializada. El fenómeno se propagó a otros países, pues tratando de recuperar su equilibrio intemo se vieron obligados a abandonar el sistema de tipos de cambio fijos y permitir la flotación de sus monedas.
En 1976 se reformó el sistema monetario internacional y se legalizaron los tipos de cambio flotantes en una serie de países. El Convenio Constitutivo del Fondo Monetario Internacional se enmendó con el objetivo de relacionar la estabilidad de los tipos de cambio con la estabilidad de variables económicas y financieras. Las nuevas circunstancias que empezaron a delinearse en la década de 1970 crearon un ambiente propicio para la especulación e intensificaron los disturbios en las relaciones monetarias internacionales, fluctuaciones en las tasas de interés, movimientos de capital internacional y problemas de fugas de capitales y de deuda externa.

Al respecto, Correa (1992) señala que la crisis, que empezó a gestarse a partir de los setenta, ha significado una desarticulación de las formas de reparto del excedente económico, mientras los aparatos financieros locales se van abrien do a otras estructuras de valorización del capital que también la crisis mantiene en reconfiguración. Además, Correa menciona que la devaluación de la libra esterlina en 1967, seguida del doble mercado del oro, de la devaluación del franco y de la revaluación del marco, hasta la supresión de la convertibilidad del dólar y, con todo ello, la ruptura del orden monetario de Bretton Woods en agosto de 1971, marcan el inicio de las grandes y recurrentes crisis financieras en el mundo. 3 y 4

Según López (2006), otra consecuencia de las devaluaciones del dólar que dieron pie a la ruptura del sistema internacional de paridades fue que todos los países experimentaran un empobrecimiento relativo, al ver disminuido el valor de sus reservas internacionales denominadas en la moneda estadounidense. 5

Puyana (2002) argumenta que a partir de 1973 los principales países industrializados procedieron paulatinamente a abolir todas las restricciones a los movimientos internacionales de capital, es decir, a desregular la cuenta de capitales de la balanza de pagos. El resultado, continúa el autor, fue un crecimiento exponencial del volumen de flujos internacionales de capital. 2

Se sostiene que los cambios en la forma de acumular capital obligaron a las economías de los países en desarrollo a aplicar reformas radicales, como parte de sus programas de ajuste y estabilización, que implicaron un cambio drástico en la estrategia de crecimiento y desarrollo que hasta entonces se había seguido. Ahora, el eje del crecimiento sería el sector exportador, abandonando el viejo modelo sustitutivo de importaciones. En consecuencia, la desregulación económica, que 
implicaba liberalización comercial y fin anciera, así como el retiro del Estado de las actividades económicas, permitiría la integración de la economía al mercado internacional, en un contexto de globalización de los mercados financieros y de mercancías. 6

El economista John Williamson denominó Consenso de Washington a una serie de reformas que las economías estatizadas de América Latina debían aplicar para atraer nuevamente a los capitales privados después de la debilitante crisis de la deuda de la década perdida de los años ochenta (Clift, 2003). En pocas palabras, estas políticas tenían por objeto reformar las economías de América Latina, las cuales pronto se convirtieron en un modelo para todos los países en desarrollo, políticas que enfatizaban la disciplina macroeconómica, principalmente en materia fiscal, la economía de mercado y la apertura. 7

Es así que con la ruptura del Bretton Woods, el devenir de los mercados internacionales está caracterizado por la desregulación y la innovación financiera, la incorporación de nuevas tecnologías, la renovada presencia de intermediarios financieros no bancarios y una competencia irrestricta. Sin embrago, la liberalización financiera no condujo hacia una nueva etapa de crecimiento de la inversión y del empleo en las mayores economías; por el con trario, las estructuras financieras se enfrentaron con una fragilidad que se manifiesta en crisis bancarias y financieras recurrentes. 3

De acuerdo con lo anterior, podemos afirmar que la globalización financiera provoca un aumento del riesgo de que se desencadene una crisis financiera, ya que esta aumenta la incertidumbre en los mercados financieros internacionales, principalmente en economías emergentes por los flujos de capital que ingresan a dichos países.

En estas circunstancias, lo más que podemos hacer es frenar la inestabilidad de los mercados, limitar las oscilaciones cíclicas y mejorar las técnicas de control del riesgo. Una de las primeras cuestiones es determinar las medidas que pueden adoptar los países para hacer frente a la volatilidad de los flujos de capital. La cuestión principal es como pueden contribuir en este sentido las políticas monetarias y cambiarias de ámbito nacional, así como la gestión fiscal y los controles de cambios.

En relación con lo anterior se sostiene que las únicas variables, cuya existencia se ha podido confimar empíricamente, que pueden provocar crisis son la globalización financiera, entendida como el aumento de los flujos transnacionales de capital y de la liquidez internacional, y el uso de productos financieros derivados, según Olivié (2002). 8

Entre 1994 y 1999, varios países en desarrollo experimentaron crisis financieras que deterioraron los niveles de vida y en algunos casos hicieron caer los gobiernos y empobrecieron a su población. Los responsables de las políticas económicas y financieras enfrentaron el problema del contagio financiero. Al respecto basta recordar la devaluación del peso mexicano en 1995, la crisis asiática de 1997, el desplome del rublo en la crisis rusa de 1998 y la devaluación del real brasileño en 1999.

\section{Innovación financiera como fuente de riesgos}

En las últimas décadas, los mercados financieros han estado inmersos en un proceso de innovación financiera constante. Esta innovación financiera se ha traducido, principalmente, en dos fenómenos. El primero de ellos es la consolidación de instrumentos financieros como los llamados derivados (opciones, swaps y futuros, y derivados de crédito). El ejemplo más claro de este tipo de modernización fue la titularización masiva de los instrumentos de deuda en la década de los ochenta. El segundo fenómeno derivado de la innovación financiera ha sido la aparición de nuevos comportamientos 0 costumbres por parte de los agentes financieros. Los detonantes de esta revolución financiera se encuentran en la revolución tecnológica por una parte y. por otra, en el proceso de desregulación (económica en general y financiera en particular), iniciado en la década de los setenta, que dio lugar a una mayor competencia y a un aumento de las posibilidades de inversión en los mercados financieros, pero también a una mayor volatilidad.

Según Cabello (1999), la aparición de formas novedosas de ahorro e inversión es de gran importancia en la globalización financiera, pues constituyen vehículos que hacen posible una movilización de capitales a través del mundo más ágil, facilitada aún más por los desarrollos en la informática y las telecomunicaciones. 9

No obstante, la gestión del riesgo de tipo de cambio pasó de ser responsabilidad de las autoridades a ser responsabilidad de los agentes privados: puede decirse que se "privatizó" el riesgo de tipo de cambio. Así, la consolidación de algunos productos y comportamientos se justificaba, en principio, como una forma de responder a la mayor inestabilidad y de aprovechar el acceso a nuevas fuentes de financiación facilitadas por la desregulación financiera. Sin embargo, algu nos autores sostienen que la 
innovación financiera, lejos de alcanzar su objetivo principal que era el de atenuar la creciente volatilidad en los mercados financieros, ha contribuido a aumentarla. Además, favoreció una mayor propensión al riesgo por parte de los agentes que integran los mercados financieros, todo lo cual redunda en un aumento de la fragilidad financiera (Carter, 1989). 10

Al respecto, todas las innovaciones, particularmente la desregulación financiera, apuntaron hacia una peligrosa dirección, que es la multiplicación del riesgo y la incertidumbre, lo que ha dado lugar a especulaciones nocivas, como fue el caso de los valores de mínima rentabilidad. Además, señala la autora, implica una ausencia relativa de ciertas normas indispensables en el funcionamiento de los mercados financieros.

Si bien esta postura no ha sido recogida en ningún modelo teórico, los autores que la sostienen sí han tratado de ofrecer algunas explicaciones de este fenómeno; explicaciones que se recogen a continuación: la innovación financiera contribuye, desde este punto de vista, al aumento de la volatilidad y de la fragilidad financiera mediante el aumento de la incertidumbre, el aumento del endeudamiento total de los agentes económicos, el acortamiento de los horizontes para la toma de decisiones y la mayor transmisión de shocks económicos de unos agentes a otros.

Por lo que respecta al incremento de la incertidumbre, la innovación financiera ha permitido que aumenten las posibilidades de diversificación de las carteras de los agentes económicos. Esto es así porque la mayoría de los nuevos productos y nuevos comportamientos derivados de la innovación (en particular los swaps) facilitan el acceso a gran numero de productos, con lo que los agentes que antes mantenían relaciones financieras con un número reducido de agentes tienen, gracias a la innovación financiera, la posibilidad de realizar operaciones financieras con un número mayor de agentes. Al tener cada unidad económica un mayor número de socios financieros, disminuye proporcionalmente la información que la unidad económica tiene con respecto a cada uno de sus socios, es decir, aumenta la incertidumbre respecto de los demás agentes económicos.

Pero la mayor incertidumbre no se genera únicamente entre agentes financieros privados, pues las autoridades encargadas de controlar la actividad financiera también tienen mayores dificultades para evaluar las posiciones en derivados de los agentes así como el riesgo en el que están incurriendo. Aumenta por tanto la incertidumbre de las autoridades monetarias con respecto a los agentes privados, lo cual merma su eficacia para controlar la actividad financiera (Shafer, 1987). Esto puede tener por consecuencia un crecimiento generalizado del volumen de endeudamiento de los agentes privados. Según Crockett (1995), esto sería así porque al burlar los requisitos de endeudamiento máximo, los agentes aprovecharán para endeudarse en mayor medida, incurriendo en un riesgo mayor. Así se puede ver cómo dos de los factores que dieron lugar al proceso de innovación financiera, la incertidumbre y la desregulación, se ven fortalecidos como consecuencia de dicha innovación.

Además, el conjunto de las innovaciones que se han producido en el terreno de las finanzas facilita la transmisión de shocks económicos de unos sistemas financieros a otros (Carter, 1989). Esto sería así porque la innovación financiera ha contribuido a una mayor integración de los mercados financieros. Entonces, los shocks económicos (tanto positivos como negativos) se contagian con mayor facilidad y rapidez de unos sistemas a otros.

Además de las distorsiones que se pueden crear en los sistemas financieros por el conjunto de innovaciones financieras realizadas en las últimas décadas, también se han denunciado algunos riesgos específicos de algunos tipos de innovaciones. Según Eatwell (1996). existen tres motivos por los cuales el uso de productos derivados pueden contribuir al aumento del riesgo: 11

1. Está la complejidad de la estructura del propio producto, que limita la capacidad de las firmas para gestionarlos correctamente y para evaluar las posiciones en derivados de los demás agentes, lo cual contribuye a un aumento aún mayor de la incertidumbre.

2. Se suelen emplear modelos matemáticos utilizados en otro tipo de ciencias como la física para calcular el precio de los productos derivados, lo que implica que los modelos de cálculo comprometen una mayor dispersión de los precios de los productos derivados, es decir, provocan un aumento de la volatilidad en los precios de dichos productos $\mathrm{y}$, por tanto, del riesgo.

3. El uso de productos derivados suele provocar problemas de liquidez a los agentes que recurren a este tipo de cobertura de riesgos. Esto es así porque la compra de estos productos suele financiarse con fondos ajenos, por lo que una caída repentina del precio de los activos puede provocar una carencia de liquidez y la imposibilidad de devolver la deuda para el tenedor del título. 
Por todos estos motivos, según Eatwell (1996), el uso de los productos financieros derivados provoca un aumento del riesgo sistémico.

\section{Conclusiones}

La globalización financiera es un proceso histórico en marcha, en el cual la innovación financiera ha jugado un papel preponderante gracias al desarrollo de nuevas tecnologías en los ámbitos de la información y la comunicación que aplicados al sector financiero se han convertido en oportunidades para el mundo de las inversiones y el financiamiento, pero al mismo tiempo en una fuente de riesgos financieros para las empresas y las economías.

\section{Referencias}

[1[Giddy, Ian H. 1994. Global financial markets, D. C. Heath and Company. Lexington, Massachusetts.

[2] Puyana, Jaime. 2002. Globalización, neoliberalismo y la crisis a siática: la necesidad de un nuevo orden financiero internacional. UNAM.

[3] Correa, Eugenia. 1992.Los mercados financieros y la crisis en América Latina. IIEc-UNAM.

[4] Correa, Eugenia. 1998. Crisis y desregulación financiera. UNAM IIEcSiglo XXI

[5] López, Francisco. 2006. Factores macroeconómicos y rendimientos accionarios: modelos multifactoriales del riesgo sistemático de los mercados de capitales de México, Canadá y Estados Unidos. Tesis doctoral, UNAM.

[6] López, Teresa. 2003. Libera lización financiera, esterilización monetaria y desintermediación bancaria en México. Miguel Ángel Porrúa-UNAM

[7] Clift, Jeremy. 2003. Más allá del Consenso de Washington, Finanzas y Desarrollo, FMI, vol. 40 no.3, Washington, D.C.

[8] Olivié, Iliana. 2002. Globalización financiera y crisis en economías emergentes. Tesis doctoral, Universidad Complutense de Madrid.

[9] Cabello, Alejandra. 1999. Globalización y liberalización financieras y la bolsa mexicana de valore. Del auge a la crisis. Plaza y Valdés. México.

[10] Carter, Michael. 1989. Financial innovation and financial fragility, Journal of Economic Issues, vol. XXIII, no. 3-4.

[11] Eatwell, John. 1996. International ca pital libera lisa tion: the impact on the world development. CEPA working papers, serie 1, no. 1 . New school for social research. 